\title{
Morphometry of iliotibial tract and its surgical importance: an
}

\section{anatomical study}

\author{
Hosapatna M', Ankolekar VH², Das A ${ }^{3}$, Sylvan A D Souza ${ }^{4}$, Anne D Souza ${ }^{5}$ \\ ${ }^{1}$ Dr. Mamatha Hosapatna (M.D Anatomy), Associate Professor, ${ }^{2}$ Dr. Vrinda Hari Ankolekar (M.D Anatomy), Associate \\ Professor, ${ }^{3}$ Dr. Aswin Das (MBBS), Postgraduate Student ${ }^{4}$ Dr. Antony Sylvan D Souza (M.S Anatomy), Professor, ${ }^{5}$ Dr. \\ Anne D Souza (M.D Anatomy), Assistant Professor. All are affiliated with Department of Anatomy, Kasturba Medical \\ College, Manipal University, India
}

Address for Correspondence: Dr. Anne D Souza, Assistant Professor, Department of Anatomy, Kasturba Medical College, Manipal University, India, Email id: annedsouza_84@yahoo.co.in

\begin{abstract}
Background: The fascia lata thickens over the lateral surface of thigh to form a strong band iliotibial tract. It is considered as an anterolateral knee stabilizer. Methods: The present study was carried out in 16 right and 8 left dissected lower limbs. The soft tissue was dissected and fasicalata was visualized. The ITT was defined from the iliac crest to its attachment to the tibia. Tendon of biceps femoris (BF) was identified. All the extensions of ITT were identified near its lower attachment to the tibia. The bony landmarks taken for measurements were anterior superior iliac spine (ASIS), tubercle of iliac crest (TIC), Gerdy's tubercle on the tibia (GT), superior border of patella (SP) and most prominent point on medial malleolus (MM). Results: In the present study the length of ITT from TIC to the GT was $53.5 \pm 3.13 \mathrm{~cm}$ on right side and $53.37 \pm 4.49 \mathrm{~cm}$ on left side. The width of ITT at the level of superior border of patella was $2.47 \pm 0.49 \mathrm{~cm}$ on right side and $2.17 \pm 0.27 \mathrm{~cm}$ on left side. The distance of ITT from GT to BF insertion was $2.86 \pm 0.49 \mathrm{~cm}$ on right side and $2 \pm .0 .11 \mathrm{~cm}$ on left side. The average extension of TFL from TIC was $16.00 \pm 1.29 \mathrm{~cm}$ and $19.5 \pm 3.64 \mathrm{on}$ right and left sides respectively. Conclusion: The morphometry of ITT and its extensions are important not only in diagnosis of the pathologies related to it but also for a safer surgical approach.
\end{abstract}

Key words: Iliotibial Tract, Knee Stabilizer, Tensor Fascia Lata, Gerdy's Tubercle, Morphometry

Manuscript Received: $14^{\text {th }}$ Sept 2015

Reviewed: $24^{\text {th }}$ Sept 2015

Author Corrected: $30^{\text {th }}$ Sept 2015

Accepted for Publication: $6^{\text {th }}$ Oct 2015 


\section{Introduction}

The fascia lata thickens over the lateral surface of thigh to form a strong band iliotibial tract (ITT). The upper end of tract splits into 2 layers and encloses tensor fascia lata (TFL).

Superficial layer attached to iliac crest, the deeper layer blends with the lateral part of capsule of hip joint. Distally it is attached to a smooth triangular facet that is Gerdy's tubercle.

When the knee is extended against resistance it stands out as strong visible ridge on the anterolateral aspect of the thigh [1].

ITT provide insertion to tensor fascia lata and gluteus maximus muscle, it plays a crucial role to stabilize knee in extended position.

The detailed description of the structures forming ITT playsan important role in the study of knee instabilities. It's important tibial, femoral,

and patellar connections are described for the better understanding of tibial-femoral instability [2].

ITT is a complex structurereceiving the insertions of the gluteus maximus and TFL muscles. The ITT together with the TFL and the gluteus maximus fibers play a role on the stance phase of the gait and in monopodal balance $[3,4]$.

Thus the ITT is a ligament of great strength and some elasticity. But it is amost unusual ligament, for it crosses two joints. Because of this, its effect on the knee must vary according to the position of the hip. At the knee it is lax infull flexion and tight in extension [5].

Therefore the present study was undertaken to describe the morphometry of ITT, its extensions and also the extension of TFL and their surgical importance.

\section{Material and Methods}

The present study was carried out in the department of Anatomy, Kasturba Medical College, Manipal. 16 right and 8 left dissected lower limbs were used for the study.

The soft tissue was dissected and fasicalata was visualized. The ITT was defined from the iliac crest to its attachment at the tibia. Tendon of biceps femoris (BF) was identified. All the extensions of ITT were identified near its lower attachment to the tibia.

The bony landmarks taken for the measurements were anterior superior iliac spine (ASIS), tubercle of iliac crest (TIC), Gerdy's tubercle on the tibia (GT), superior border of patella (SP) and most prominent point on the medial malleolus (MM). The important landmarks are shown in figure 1. 
The following parameters were measured;

1. Length of the lower limb (ASIS to MM)

2. Length of ITT (TIC to GT)

3. Width of ITT at the level of superior border of patella

4. Distance between GT to the attachment of tendon of

$\mathrm{BF}$

\section{Results}

The mean and standard deviations of the measured parameters are shown in table 1.

The extensions of ITT were noted in all specimens to patella, tendon of BF and also to the tibia (Figure2).

Independent sample t-test was used to compare the means of right and left sides which did not show any statistical significance.

Pearson's correlation test was applied to correlate the length of lower limb and that of ITT. There was a strong positive correlation between the two which was statistically significant $(r=0.9, p<0.001)$. No correlation was found between the length of ITT and its width $(\mathrm{r}=-0.06)$

Table 1: Mean and SD of the parameters measured.

\begin{tabular}{|c|c|c|}
\hline Parameters measured in cm & Right $(\mathbf{N}=16)$ & Left (N=8) \\
\hline Length of lower limb & $83.81 \pm 5.12$ & $84.00 \pm 7.52$ \\
\hline Length of ITT & $53.5 \pm 3.13$ & $53.37 \pm 4.49$ \\
\hline Width of ITT & & $2.17 \pm 0.27$ \\
\hline GT to insertion of BF & $2.47 \pm 0.49$ & $2.00 \pm 0.11$ \\
\hline Length of TFL & & $19.5 \pm 3.64$ \\
\hline
\end{tabular}

ITT- iliotibial tract, GT- Gerdey's tubercle, BF- biceps femoris, TFL- tens 
Original Article

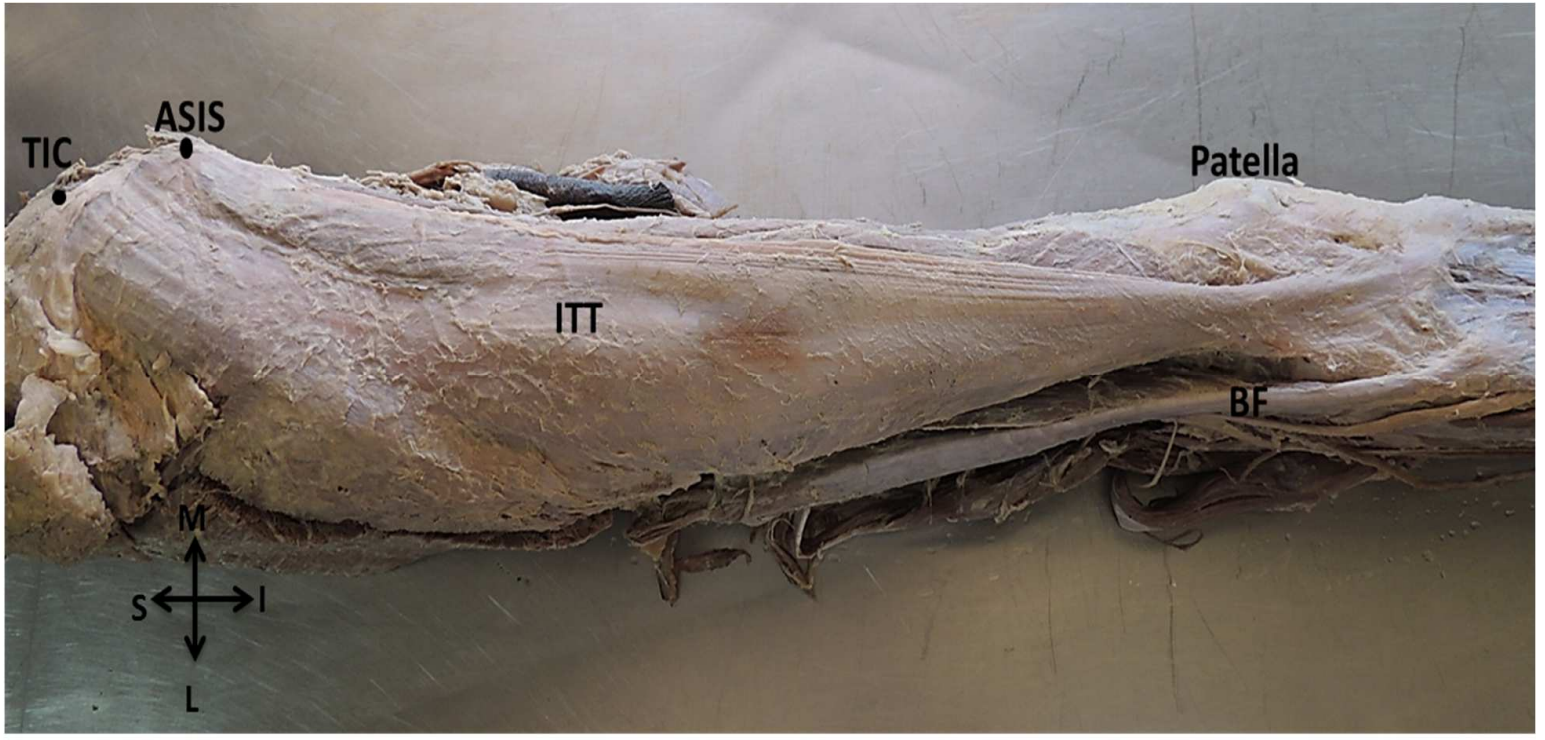

Figure 1: Iliotibial tract and the bony landmarks.

ASIS- Anterior superior iliac spine, TIC- Tubercle of iliac crest, ITT- Iliotibial tract, BF- Biceps femoris

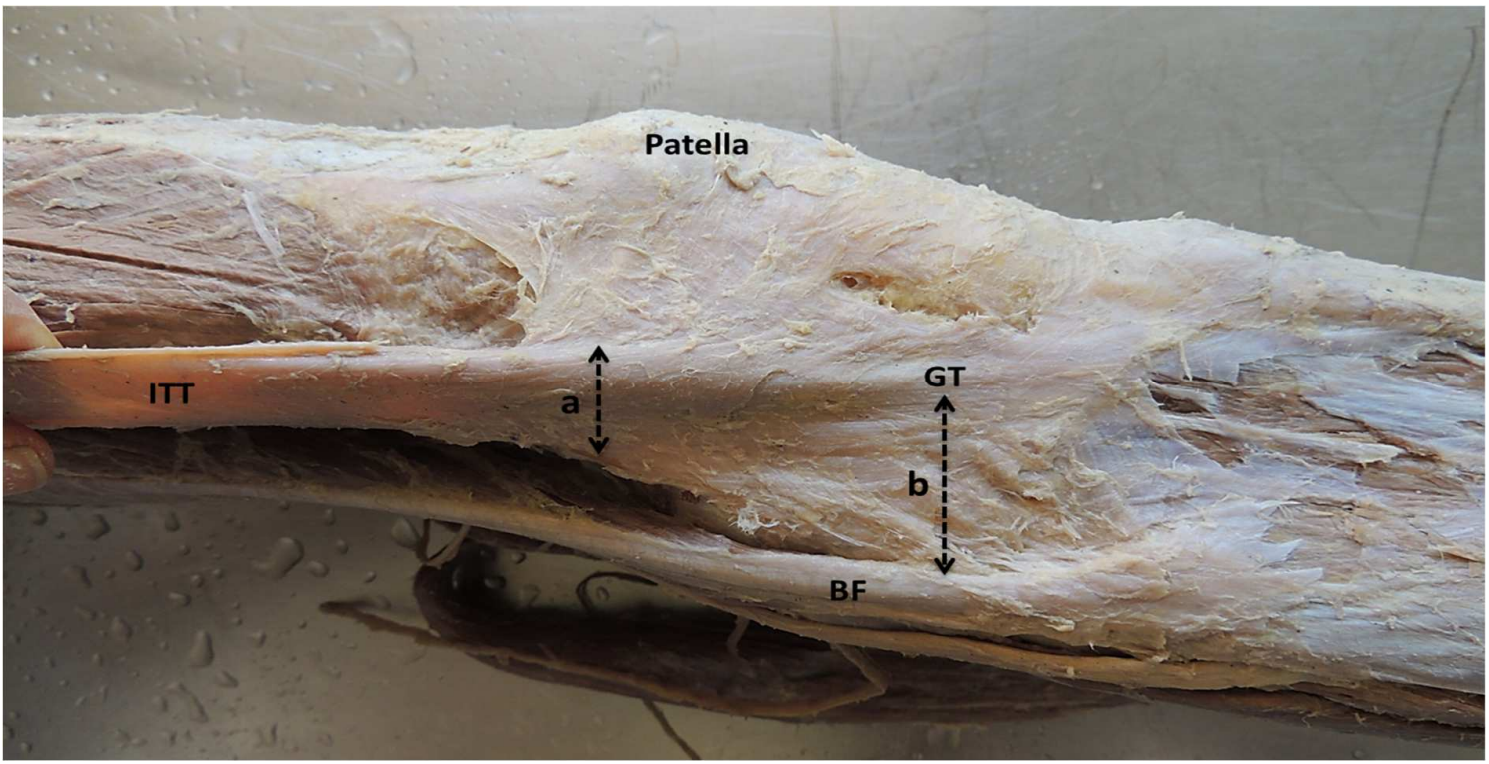

Figure 2: Lateral aspect of knee showing the distal attachment of Iliotibial tract.

ITT- Iliotibial tract, BF- Biceps femoris, GT- Gerdey’s tubercle

a- $\quad$ Width of ITT at the level of superior border of patella

b- Distance between ITT and BF at the level of Gerdey's tubercle 


\section{Original Article}

\section{Discussion}

The ITT is a thickening of the deep fascia of thelateral aspect of the thigh. Proximally, it encloses the tensor fascia lata and up to three-quarters of the gluteus

maximus inserts into it posteriorly. It has several bony attachments: it is anchored to the iliac crest terminating proximal to the lateral femoral epicondyle [6,7]. It is also attached to the Gerdy's tubercle on the tibia.

Recent works have described important connections of the ITT to the patella [2]. Clinical studies have suggested that the ITT has an important synergistic role with the anterior cruciate ligament [8].

According to Tandler the parallel muscle bundles of gluteus maximus continue just behind the greater trochanter as a flat and large tendon, which is continuous to the strengthened portion of the fascia lata, constituting the iliotibial ligament or Maissiat's band, which extends from the iliac crest to the tibial lateral condyle. These insertions are very important because they enable the ITT to be tense in the entire joint [9].

In the present study the length of ITT from TIC to the GT was $53.5 \pm 3.13 \mathrm{~cm}$ on right side and $53.37 \pm 4.49 \mathrm{~cm}$ on left side. The width of ITT at the level of superior border of patella is $2.47 \pm 0.49 \mathrm{~cm}$ on right side and 2.17 $\pm 0.27 \mathrm{~cm}$ on left side. According to Kaplan the length and insertions of ITT play the role of a tension band at the thigh and keeps it always tense in the entire joint movement range being important for the functional stability [6].

The Iliotibial band is frequently involved in friction syndrome occurring commonly due to its overuse. Vasilevska's group studied patients with osteoarthritisof the medial compartment of the knee and found a high incidence of iliotibial band friction syndrome [10].

The distance of ITT from GT to BF insertion was $2.86 \pm 0.49 \mathrm{~cm}$ on right side and $2 \pm .0 .11 \mathrm{~cm}$ on left side.The average extension of TFL from TIC was $16.00 \pm 1.29 \mathrm{~cm}$ and $19.5 \pm 3.64$ on right and left sides respectively. The authors were unable to compare these parameters due to the lack of available literature.

The TFL perforator flap is considered to be an alternative to the anterolateral thigh flap which is useful for the reconstruction of different anatomical districts [11].

The morphometry of ITT plays an important role in endoscopic approach for trochanteric bursitis or greater trochanteric pain syndrome.

This endoscopic technique includes bursectomy and ITT release and is a good alternative to open treatment. This minimally invasive approach leads to a quicker recovery and should therefore, in our opinion, be 


\section{Original Article}

preferred above an open technique [12]. The morphometry of ITT and its extensions are important not only in diagnosis of the pathologies related to it but also for a safer surgical approach.

Conflict of interest: None declared.

Funding: Nil, Permission from IRB: Yes

\section{References}

1. Standring Susan. Grays Anatomy- The anatomical basis of clinical practice. Philadephia: Elsevier Churchill Livingstone, 2008, London, 40th edn, pp1349- 50.

2.Vieira EL, Vieira EA, da Silva RT, Berlfein PA, Abdalla RJ, Cohen M. An anatomic study of the iliotibial tract. Arthroscopy. 2007 Mar;23(3):269-74.

3. Henry AK. Extensile exposures. $2^{\text {nd }}$ edn. Baltimore: William \&Wilkins, 1957, pp-237.

4. Maquet PGL. Mechanics of the knee. In: Biomechanics of the knee. Berlin ; Springer-Verlag, 1984, pp-22.

5. Inman VT, Saunders JB. Anatomicophysiological aspects of injuries to the intervertebral disc. J Bone Joint Surg Am. 1947 Apr;29(2):461-75.

6. KAPLAN EB. Some aspects of functional anatomy of the human knee joint. Clin Orthop. 1962;23:18-29.
7.Terry GC, Hughston JC, Norwood LA. The anatomy of the iliopatellar band and iliotibial tract. Am J Sports Med. 1986 Jan-Feb;14(1):39-45.

8.Terry GC, Norwood LA, Hughston JC, Caldwell KM. How iliotibial tract injuries of the knee combine with acute anterior cruciate ligament tears to influence abnormalanterior tibial displacement.. Am J Sports Med. 1993 Jan-Feb;21(1):55-60.

9. Tandler J. Sistema muscular. In: Tratado de anatomiasistemática. Barcelona: Salvat, 1928, pp-423424.

10.Vasilevska V, Szeimies U, Stäbler A. Magnetic resonance imaging signs of iliotibial band friction in patients with isolated medial compartmentosteoarthritis of the knee. Skeletal Radiol. 2009 Sep;38(9):871-5. doi: 10.1007/s00256009-0704-z. Epub 2009 May 30.

11. Federico C, Negosanti L, PintoV, Tavaniello B, Fabbri E, Sgarzani R et al. Tensor fascia latae perforator flap: An alternative reconstructive choice for anterolateral thigh flap when no sizable skin perforator is available. Indian journal of plastic surgery. 2013;46(1):55-58.

12.Govaert LH, van Dijk CN, Zeegers AV, Albers GH. Endoscopic bursectomy and iliotibial tract release as a treatment for refractory greater trochanteric pain syndrome: a new endoscopic approach with early results. Arthrosc Tech. 2012 Aug 24;1(2):e161-4. doi: 10.1016/j. eats.2012.06.001. Print 2012 Dec. 


\section{How to cite this article?}

Hosapatna M, Ankolekar VH, Das A, Sylvan A, D Souza, Anne D Souza. Morphometry of iliotibial tract and its surgical importance: an anatomical study. Int J surg Orthopedics 2015;1(1):10-16. doi: 10.17511/ijoso.2015.i1.03. 